\title{
EARLY NEUROLOGICAL DETERIORATION IN ACUTE ISCHEMIC STROKE: POTENTIAL PREDICTORS, CAUSES AND RELATION TO INFARCT GROWTH
}

\author{
Samia Ashour Mohamed Helal, Hany Amin Aref, Ayman Mohammed Nassef, \\ Ramez Reda Moustafa, Mohammed Amir Tork, Ehab Abd Elbaset Abdulsamad*
}

Department of Neurology, Faculty of Medicine, Ain Shams University, Cairo, Egypt.

Corresponding :

Ehab Abd Elbaset Abdulsamad Mobile: Tel. 01091205400

E mail:

m_amirtork@yahoo.com Received: 29/10/2019

Accepted: 26/11/2019

\begin{abstract}
:
Background: Worsening of acute stroke early in its course (within 48-72 $h$ of its onset) is a common occurrence and has potentially serious short term and long term consequences. The incidence of early neurological deterioration (END) among hospitalized patients varies widely in different studies between $13 \%$ and $38 \%$.
\end{abstract}

Aim of the Work: To define incidence and timing of END in relation to acute ischemic stroke (AIS) onset. To identify possible causes and predictors associated with END. To assess the relation between END and the patient functional level at three months post stroke.

Patients and Methods: Three hundred patients were recruited into this hospital prospective comparative study. Clinical history, laboratory indices, structural brain imaging, Magnetic Resonance Angiography (MRA) and Carotid Duplex ultrasonography were done. Patients were examined on NIHSS and Glasgow Coma Scale (GCS) in day 1, 2, 3 and patients with END did a follow up (MRI diffusion film or CT brain) at day4 or 5 and all patients were followed up by Modified Rankin scale (MRs) at three-month post stroke.

Results: Of the Three hundred patients included in the study, the incidence of END was $16.7 \%$. The median NIHSS on admission was 9.25. END was associated with long duration of DM (P 0.012), IHD ( $p$ 0.015), AF ( $p$ 0.048), severe stroke ( $p$ 0.0044), low blood pressure on admission ( $p$ 0.0079), high uric acid ( $p$ 0.033) and MCA occlusion (p 0.0007). END was associated with significant increase in MRS at 3 month $(p<0.0001)$ and mortality rate (44\% vs 4.4). Patients with END are more prone for aspiration pneumonia ( $p$ 0.0001) and hemorrhagic transformation.

Conclusion: Early neurological deterioration is a frequent complication after acute stroke, with a poor short-term prognosis. This study provides that hyperglycemia, hyperuricemia and cardiac disease (IHD and AF) may increase the risk of END. Stroke.

Keywords: Early Neurological Deterioration, Acute Ischemic

\section{INTRODUCTION:}

Worsening of acute stroke early in its course (within $48-72 \mathrm{~h}$ of its onset) is common and has potentially serious short term and long term consequences for the patient $^{(\mathbf{1})}$. Various terms, such as "progressive stroke", ' stroke in evolution", and "stroke in progression" have been used to describe this worsening ${ }^{(2)}$. Now most 
commonly termed early neurological deterioration (END) ${ }^{(3)}$.

END was defined in the European progressing stroke study (EPSS) as any significant neurological deterioration from baseline to 72 hours $^{(3)}$.

A significant neurological deterioration was primarily defined as a decrease in the Scandinavian stroke scale (SSS) items score for consciousness, speech, gaze, arm, or leg by at least 2 points. Consciousness was given precedence over the other signs ${ }^{(3)}$.

Many studies considered increase in the total national institute of health stroke scale (NIHSS) score by at least 2 points a significant neurological deterioration ${ }^{(3,4)}$. Others considered increase in the total (NIHSS) score by at least 4 points ${ }^{(5)}$. Bathia and his colleague considered increase in the total (NIHSS) score by at least 3 points ${ }^{(6)}$. Siegler and his colleague compared between the increase in the NIHSS score by $\geq 2$ or $\geq 4$ points and founded that $A \geq 2$ point neurological deterioration is a sensitive indicator of poor outcome and in hospital mortality $^{(7)}$.

The incidence of END in ischaemic stroke among hospitalized patients varies widely in different studies. $19 \%$ of acute stroke patients had $\mathrm{END}^{(\mathbf{8})}, 28 \%{ }^{(\mathbf{9})}$, $37.5 \%{ }^{(\mathbf{1 0 )}}$. In the Harvard Cooperative Stroke Registry that included haemorrhagic and non haemorrhagic strokes, early worsening was noted in $20 \%$ of patients ${ }^{(\mathbf{1 1})}$. In the Barcelona Stroke Registry of 3577 consecutive patients hospitalized with stroke (all types), 37\% showed $\mathrm{END}^{(\mathbf{1 2})}$. Rates of $29 \%$ and $25 \%$, respectively, were reported for all acute strokes in Swiss ${ }^{\mathbf{1 3})}$ and Japanese ${ }^{(\mathbf{1 4 )}}$ studies.

The differences in the time scale of assessments after acute stroke, diagnostic criteria used for END, and the case mix of stroke patients could account for the wide variations reported in the studies. Even among ischaemic strokes, subtypes differ in the rates of END ${ }^{(15)}$.
END after acute ischemic stroke (AIS) has been found to be related to case fatality and reduced functional outcome ${ }^{(\mathbf{1 6})}$. Various mechanisms and predictors have been postulated to explain $\mathrm{END}^{(\mathbf{3})}$.

\section{AIM OF THE WORK:}

- To define the incidence, severity and timing of END in relation to AIS onset

- $\quad$ To identify factors and possible causes and predictors associated with END after AIS

- To assess the relation between END after AIS and the patient functional level at three months post stroke including case fatality

\section{PATIENTS AND METHODS:}

\section{Methods:}

A hospital based prospective observational study carried out during the period from January 2017 to June 2018 at Ain Shams University Hospitals.

The definition of END was (increase in the National Institute of Health Stroke Score (NIHSS) by two or more points (or stroke related death) between admission and day $3)$.

\section{Patients included in the study subjected} to:

\section{Clinical Data}

Full clinical history and examination was obtained by a trained neurologist. The following data were expressly recorded for analysis:

Age, Sex, Smoking status, Diabetes Mellitus, hypertension, hyperlipidemia, heart disease (ischemic and otherwise) and History of previous Transient Ischemic Attacks (TIA) and/or stroke. 


\section{Laboratory Indices}

The patients had the following laboratory tests done (venous blood samples):

Complete Blood Count, Fasting and glycosylated hemoglobin (HBA1c), Serum lipid profile, Serum Uric Acid (Hyperuricaemia was defined as serum uric acid above 7.0 in men or above 6 in women), Renal function tests (serum creatine and blood urea nitrogen), Liver function tests (liver enzymes, serum albumin and coagulation profile and Electrolytes (sodium, potassium and calcium).

\section{Structural Brain Imaging:}

\section{Magnetic Resonance Imaging:}

Magnetic Resonance Imaging (MRI) of the brain was done on a 1.5 tesla General Electric system (Signa Prospeed LX). The imaging protocol included the following sequences: Fast Spin Echo (FSE) Axial T1weighted imaging, Axial T2-weighted imaging, Axial Fluid Attenuated Inversion Recovery (FLAIR), axial single-shot multislice diffusion-weighted echo-planar imaging pulse sequence (DWI-EPI) and Axial EPI Gradient Echo T2*. MR angiography was performed during the same session when available as detailed below.

\section{Vascular Imaging}

\section{Magnetic Resonance Angiography}

Three-dimensional Time-of-flight (TOF) Magnetic Resonance Angiography of the cerebral vessels was done on a 1.5 tesla General Electric machine (Signa Prospeed LX). The images were calibrated and visually inspected for presence of stenosis or occlusion of the major arteries on both sides (ICA, M1 of MCA, P1 of PCA and BA).

\section{Carotid Doppler Ultra sonography}

This was done on by a trained radiologist using a $7.5 \mathrm{MHz}$ transducer on a Philips ultrasound machine. Peak Systolic Flow and Mean Flow Velocities were measured for the common carotid (CCA), the internal carotid and the external carotid arteries on both sides.

Significant stenosis of the carotid arteries was defined as $>70 \%$ narrowing.

\section{Echo Cardiography:}

To detect cardiac source of emboli and manifestations of long standing hypertension (HTN).

Trans thoracic Echo was done for all patients (trans esophegeal for selected patients) to detect: Atrial diameter, ejection fraction, cardiomyopathy and intracardiac thrombus.

ECG: To detect AF.

- All patients were examined on NIHSS and Glasgow Coma Scale (GCS) in the 1-2-3 day.

- All patients with END did a follow up MRI diffusion film or CT at day 5.

- All patients were followed up by Modified Rankin scale (MRs) at threemonth post stroke.

\section{Statistical Analysis:}

Data entry, processing and statistical analysis was carried out using Med Calc ver. 18.2.1 (Med Calc, Ostend, Belgium). Tests of significance (Mann-Whitney's, and Chi square tests, logistic regression analysis, and Spearman's correlation) were used. Data were presented and suitable analysis was done according to the type of data (parametric and non-parametric) obtained for each variable. P-values less than 0.05 $(5 \%)$ was considered to be statistically significant.

\section{RESULTS:}

\section{Baseline data:}

The mean age of all patients was $(61.83$ $\pm 11.5)$ years. Regarding gender of the patients, the majority $(66.7 \%)$ of patients were males, while $(33.3 \%)$ were females. 
HTN was prevalent among study population $(67.9 \%)$ with average duration of $(11.2 \pm$ $6.78)$ years, $(50 \%)$ of patients had DM with average duration of $(14.58 \pm 8.6)$ years, (13.3\%) had AF and (35\%) had ischemic heart disease (IHD).

Table 1: Co -morbidities among 300 AIS patients:

\begin{tabular}{|l|c|}
\hline \multicolumn{1}{|c|}{ Variables } & Frequency (\%) \\
\hline HTN & $203(67.9 \%)$ \\
\hline DM & $150(50 \%)$ \\
\hline AF & $40(13.3 \%)$ \\
\hline IHD & $105(35 \%)$ \\
\hline Hyperlipidemia & $23(7.7 \%)$ \\
\hline Collagen disease & $2(0.7 \%)$ \\
\hline Previous Stroke & $62(20.7 \%)$ \\
\hline TIA & $15(5 \%)$ \\
\hline Variable & Mean \pm SD \\
\hline Duration of HTN & $11.2 \pm 6.78 \mathrm{y}$ \\
\hline Duration of DM & $14.58 \pm 8.6 \mathrm{y}$ \\
\hline
\end{tabular}

HTN: hypertension, DM: diabetes mellitus, IHD: ischemic heart disease. AF: atrial fibrillation. TIA: transient ischemic attacks.

\section{Echocardiography and carotid duplex parameters}

Regarding baseline Echocardiography data; the mean LAD was $(39.38 \pm 5.1) \mathrm{mm}$; the mean EF was $(59.7 \pm 11.1) \%$, with $(2.9 \%)$ had intra-arterial or ventricular thrombus, and (4.4\%) had cardiomyopathy.

Regarding baseline Carotid Duplex data; $(5.2 \%)$ had Lt-sided significant stenosis, and (4.2\%) had Rt-sided significant stenosis.

\section{Follow up data:}

Regarding Follow up clinical outcomes: (8\%) had chest complications, (1.7\%) had abdomen complications (hematemesis), $(2.7 \%)$ had cardiac complications, and (3.7\%) had UTI complication.

\section{Comparative studies:}

The 300 AIS patients were classified according to (Early Neurological Deterioration) END outcomes into 2independent groups:

- END group (50 patients)*based on NIHSS change $\geq 2$ from baseline.

\section{- No END group (250 patients)}

Table 2: Follow up clinical data among 300 AIS patients:

\begin{tabular}{|l|c|}
\hline \multicolumn{1}{|c|}{ Variables } & Mean \pm SD \\
\hline SBP-1 $(\mathrm{mmHg})$ & $155.78 \pm 23.1$ \\
\hline SBP-2 & $144.16 \pm 20.1$ \\
\hline SBP-3 & $136.5 \pm 23.62$ \\
\hline DBP-3 & $80.88 \pm 12.7$ \\
\hline GCS-1 & $14.72 \pm 0.94$ \\
\hline GCS-2 & $14.62 \pm 1.2$ \\
\hline GCS-3 & $14.3 \pm 2$ \\
\hline NIHSS-1 & $9.15 \pm 4.65$ \\
\hline NIHSS-2 & $8.28 \pm 4.73$ \\
\hline NIHSS-3 & $7.74 \pm 5.1$ \\
\hline MRS (3-months) & $2.12 \pm 1.87$ \\
\hline Variables & Frequency $(\%)$ \\
\hline Chest complications & $24(8 \%)$ \\
\hline $\begin{array}{l}\text { Abdomen complications } \\
\text { (hematemesis) }\end{array}$ & $5(1.7 \%)$ \\
\hline Cardiac complications & $8(2.7 \%)$ \\
\hline UTI & $11(3.7 \%)$ \\
\hline DVT & $0(0 \%)$ \\
\hline
\end{tabular}

UTI: Urinary tract infection. DVT: deep venous thrombosis. SBP: systolic blood pressure (day- 1, 2, 3). DBP: diastolic blood pressure (day-2, 3). GCS: Glasgow coma scale (day-1, 2, 3). NIHSS: National institute of health stroke scale (day-1, 2, 3). MRS: Modified Rankin Scale

Comparative studies are shown in the following tables and figures;

\section{Baseline data:}

Comparative study between the 2 groups revealed non-significant difference as regards all basic demographic data $(\mathrm{p}>$ $0.05)$. 
Table 3: Comparison between the 2 groups as regards basic demographic data using Mann-Whitney's $\mathrm{U}$ and Chi square tests:

\begin{tabular}{|c|c|c|c|c|}
\hline \multicolumn{2}{|c|}{ Variable } & $\begin{array}{l}\text { END group } \\
(50)\end{array}$ & $\begin{array}{l}\text { No END group } \\
(250)\end{array}$ & $\begin{array}{l}\text { Mann-Whitney's U } \\
\text { test }\end{array}$ \\
\hline & & & & \\
\hline \multirow{2}{*}{\multicolumn{2}{|c|}{ Variable }} & \multirow{2}{*}{$\begin{array}{c}\text { END group } \\
(50)\end{array}$} & \multirow{2}{*}{$\begin{array}{c}\text { No END group } \\
(250)\end{array}$} & Chi square test \\
\hline & & & & $P$ value \\
\hline Gender & $\begin{array}{l}\text { Female } \\
\text { Male }\end{array}$ & $\begin{array}{l}19(38 \%) \\
31(62 \%) \\
\end{array}$ & $\begin{array}{c}81(32.4 \%) \\
169(67.6 \%) \\
\end{array}$ & $=0.4440$ \\
\hline Handiness & $\begin{array}{l}\mathrm{Lt} \\
\mathrm{Rt}\end{array}$ & $\begin{array}{c}3(6 \%) \\
47(94 \%) \\
\end{array}$ & $\begin{array}{c}9(3.9 \%) \\
241(96.4 \%)\end{array}$ & $=0.4300$ \\
\hline Smokers & $+\mathrm{ve}$ & $8(16 \%)$ & $40(16 \%)$ & $=1.000$ \\
\hline Ex-smokers & $+\mathrm{ve}$ & $1(2 \%)$ & $14(5.6 \%)$ & $=0.2871$ \\
\hline
\end{tabular}

\section{Follow up data:}

Comparative study between the 2 groups revealed; highly significant decrease in day-1, day-2 and day-3 SBP and DBP, in END group; compared to non-END group; with highly significant statistical difference $(\mathrm{p}<0.05)$, highly significant increase in chest, abdomen, cardiac complications, in END group; compared to non-END group; with highly significant statistical difference $(\mathrm{p}<0.05)$ and non-significant difference as regards UTI and DVT complications $(\mathrm{p}>$ $0.05)$.

Table 4: Comparison between the 2 groups as regards Follow up clinical outcomes:

\begin{tabular}{|l|c|c|c|}
\hline \multirow{2}{*}{ Variable } & $\begin{array}{c}\text { END group } \\
(50)\end{array}$ & $\begin{array}{c}\text { No END group } \\
(250)\end{array}$ & Mann-Whitney's U test \\
\cline { 2 - 4 } & Median (IQR) & Median (IQR) & P value \\
\hline SBP-1 & $140(130-160)$ & $155(135-170)$ & $0.0079 * *$ \\
\hline DBP-1 & $90(80-90)$ & $90(80-100)$ & $0.0083^{* *}$ \\
\hline SBP-2 & $130(120-150)$ & $150(130-160)$ & $=0.0036^{* *}$ \\
\hline DBP-2 & $80(70-90)$ & $80(80-90)$ & $=0.0036^{* *}$ \\
\hline SBP-3 & $130(120-150)$ & $140(130-150)$ & $=0.0078^{* *}$ \\
\hline DBP-3 & $80(70-90)$ & $80(80-90)$ & $=044^{*}$ \\
\hline & END group & No END group & Chi square test \\
\cline { 2 - 3 } Variable & $(50)$ & $(250)$ & P value \\
\hline Chest complications & $13(26 \%)$ & $11(4.4 \%)$ & $=0.0001^{* *}$ \\
Hematemesis & $3(6 \%)$ & $2(0.8 \%)$ & $<.0089^{* *}$ \\
Cardiac complications & $6(12 \%)$ & $2(0.8 \%)$ & $=0001^{* *}$ \\
UTI complication & $3(6 \%)$ & $8(3.2 \%)$ & $=0.3370$ \\
DVT complication & $0(0 \%)$ & $0(0 \%)$ & $=1.000$ \\
Seizure & $1(2 \%)$ & $0(0 \%)$ & $=0.025^{*}$ \\
\hline
\end{tabular}

*significant. **highly significant. UTI: Urinary tract infection. DVT: deep venous thrombosis. SBP: systolic blood pressure (day-1, 2, 3). DBP: diastolic blood pressure (day-1, 2, 3).

Comparative study between the 2 groups revealed; highly significant increase in day-1, 2 and 3 NIHSS scores, in END group; compared to non-END group; with highly significant statistical difference $(\mathrm{p}<$ $0.05)$.

Comparative study between the 2 groups revealed; highly significant increase in NIHSS change, in END group; compared to non-END group; with highly significant statistical difference $(p<0.01)$.

Comparative study between the 2 groups revealed; highly significant increase in MRS (3-months), in END group; compared to non-END group; with highly significant statistical difference $(\mathrm{p}<0.01)$. 
Table 5: Comparison between the 2 groups as regards Follow up neurological outcomes using MannWhitney's U test:

\begin{tabular}{|l|l|c|c|c|}
\hline \multicolumn{2}{|c|}{ Variable } & $\begin{array}{c}\text { END group } \\
(50)\end{array}$ & $\begin{array}{c}\text { No END group } \\
(250)\end{array}$ & Mann-Whitney's U test \\
\cline { 3 - 5 } & Median (IQR) & Median (IQR) & P value \\
\hline \multirow{4}{*}{$\begin{array}{l}\text { Neurological } \\
\text { Outcomes }\end{array}$} & GCS-1 & $15(13-15)$ & $15(15-15)$ & $0.000013^{* *}$ \\
\cline { 2 - 5 } & GCS-2 & $15(13-15)$ & $15(15-15)$ & $0.000013^{* *}$ \\
\cline { 2 - 5 } & GCS-3 & $13(11-15)$ & $15(15-15)$ & $<0.0001^{* *}$ \\
\cline { 2 - 5 } & NIHSS-1 & $12.5(9-15)$ & $7.5(4-11)$ & $<0.0001^{* *}$ \\
\cline { 2 - 5 } & NIHSS-2 & $12.5(9-15)$ & $7(4-10)$ & $<0.0001^{* *}$ \\
\cline { 2 - 5 } & NIHSS-3 & $14(10-17)$ & $6(3-9)$ & $<0.0001^{* *}$ \\
\cline { 2 - 5 } & NIHSS change & $3(3-4)$ & $-2(-4--1)$ & $<0.0001^{* *}$ \\
\cline { 2 - 5 } & MRS (3-m) & $4(2-6)$ & $2(0-3)$ & $<0.0001^{* *}$ \\
\hline
\end{tabular}

GCS: Glasgow coma scale (day-1, 2, 3). NIHSS: National institute of health stroke scale (day-1, 2, 3). MRS: Modified Rankin Scale.

Table 6: Follow up imaging for patients with END

\begin{tabular}{|l|l|}
\hline \multicolumn{1}{|c|}{ Variables } & \multicolumn{1}{c|}{ Frequency (\%) } \\
\hline Hemorrhagic transformation & $14(28 \%)$ \\
\hline Brain edema & $9(18 \%)$ \\
\hline New stroke (Progression) & $4(8 \%)$ \\
\hline
\end{tabular}

Logistic regression analysis shows that; transformation; had an independent effect on after applying (Backward method) and increasing the probability of END entering some predictor variables; the occurrence; with significant statistical increase in age, HTN duration, NIHSS- 1 , difference $(\mathrm{p}<0.05$ respectively.

DWSI, MCA, and Hemorrhagic

Table 7: Logistic regression model for the Factors affecting END occurrence:

\begin{tabular}{|l|c|c|c|}
\hline \multicolumn{1}{|c|}{ Predictor Factor } & Coefficient & Std. Error & P value \\
\hline Age Constant) & & & $0.018^{*}$ \\
\hline HTN duration & 0.23907 & 0.10120 & $0.0083^{* *}$ \\
\hline NIHSS-b & 0.72233 & 0.27350 & $0.0044^{* *}$ \\
\hline RBS & 1.00310 & 0.35256 & 0.0812 \\
\hline DWSI & 0.019366 & 0.011106 & $0.0144^{*}$ \\
\hline MCA & 11.62603 & 4.75236 & $0.0065^{* *}$ \\
\hline Hemorrhagic transformation & 6.65628 & 2.44499 & $0.0039^{* *}$ \\
\hline Brainedema & 11.56131 & 4.00902 & 0.0565 \\
\hline
\end{tabular}

Excluded from the model if ( $\mathrm{p}$ value $>0.1$ ). NIHSS: National institute of health stroke scale (baseline). HTN: hypertension. DWSI: Deep watershed infarction. MCA: Middle cerebral artery.

\section{DISCUSSION:}

Acute ischemic stroke (AIS) is a common and frequently occurring disease among middle aged and elderly population with severe disability and high mortality rate. In this prospective comparative study we evaluated early neurological deterioration (END) in AIS, its potential predictors, causes and assessed the relationship between END after AIS and the patient's functional level at three months post stroke including case fatality.

In our study, the incidence rate of END after AIS was $16.7 \%$ (50 patients). This was consistent with the overall incidence of END $(10-40 \%)$ in different studies $^{(\mathbf{1 7})}$. Similar 
results reported by lee and lee, $2017(19 \%)$ who studied 516 patients. END was defined as $\mathrm{a} \geq 2$ point increase in the National Institutes of Health Stroke Scale (NIHSS) during the first 72 hours of hospitalization.

Bathia et al studied 114 patients with acute ischemic stroke and founded that 25 patients had END (21.9\%). END was defined as $a \geq 3$ point increase in the National Institutes of Health Stroke Scale (NIHSS) during the first 72 hours of hospitalization ${ }^{(6)}$.

Percentage of END was variable between studies: Chu Huang et al studied 163 patient with anterior circulation stroke and reported 43 patients (26.4) with $\mathrm{END}^{(4)}$, Hong Geng et al. reported 32\% of 1064 patients had END (definition of END was the same of our study) ${ }^{(18)}$, Zhang et al reported $23.6 \%$ of studied patients had END

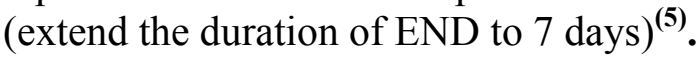

The difference in prevalence of END can be attributed to the differences in the time scale of assessments after acute stroke, diagnostic criteria used for END, and the case mix of stroke patients. Also, the implementation of stroke units specialized in treatment of AIS and the advance of new stroke management strategies (intravenous thrombolysis and mechanical thrombictomy) could account for the wide variations reported in the studies.

Regarding baseline data, there was no significant difference as regards all basic demographic data (age, sex, smoking, DM, HTN, hyperlipidemia, collagen disease, previous stroke and TIA) between patients experienced END and others $(p>0.05)$ which came in agreement with Huang et $a l^{(4)}$, and Siegler et al. ${ }^{(19)}$ (except for age), Kwan and Hand ${ }^{(8)}$ (except for smoking) and Davalos et al. ${ }^{(10)}$ and disagreement with Geng et al. ${ }^{(18)}$ for DM and HTN.

In our study, duration of DM was significantly higher in patients with END and the correlative study showed a highly significant positive correlation of HBA1c and RBS at admission with END $(p<0.05)$ which came in agreement with Bathia et $a l .{ }^{(6)}$ and Zhang et al. ${ }^{(5)}$.

In our study, IHD was significantly higher in END group compared to non-END group, with significant statistical difference $(\mathrm{p}<0.05)$ which came in agreement with Sumer et al..$^{(2)}$, and Zhang et al. ${ }^{(5)}$ in (IVrTPA group) and disagreement with Haung et al. ${ }^{(4)}$, and Geng et al. ${ }^{(18)}$.

IHD is often associated with a higher prevalence of severe extracranial and intracranial atherosclerotic disease which lead to further extension of penumbral tissue volumes and level and hence the infarction due to poor collaterals.

In our study, there was significant increase in AF in END group ( $\mathrm{p}=0.048)$ which came in agreement with Kwan and Hand, ${ }^{(8)}(33 \%$ vs $16 \%, p=0.039)$ and disagreement with Haung et al. ${ }^{(4)}$. In Echo parameters, there was no difference between END and non-END in LAD and EF ( $p>$ 0.05 ), but there was significant increase in cardiomyopathy in END group $(p=0.019)$ which came in disagreement with Aoki in $2010^{(20)}$.

Aoki et $a l^{(20)}$ reported that nonsignificant statistical difference as regard cardiac disease, which included myocardial infarction, cardiac valve disease, cardiomyopathies, and congestive heart failure.

In our study, There was highly significant decrease in baseline SBP and DBP, in END group compared to non-END group with highly significant statistical difference ( $p<0.0079,0.0085$ respectively) which came in agreement with Bathia et al. ${ }^{(6)}$ and Kwan and Hand, ${ }^{(8)}$ founded that systolic and diastolic blood pressure was lower in patients with END in comparison to non-END with no significant statistical difference disagreement with Zhang et al. ${ }^{(5)}$ and Miyamoto et al. ${ }^{(21)}$. 
In our study, there was significant increase in uric acid in END group; compared to non-END group; with significant statistical difference $(p=0.033)$ which came in agreement with ${ }^{(4 \& 22)}$.

In our study, there was negative relationship between hemoglobin level and END. Which means that high serum hemoglobin is protective against END? Anemia was reported by several studies that it had strong association with poor outcome and mortality after acute ischemic stroke (23\&24).

In our study, TLC was higher in END group but with no statistical difference which came in disagreement with Zhang et al. ${ }^{(5)}$, Bathia et al. ${ }^{(6)}$ and Kwan and Hand, ${ }^{(8)}$.

There was no significant difference as regards all the remaining laboratory variables $(p>0.05)$ which came in agreement with Lord et al. ${ }^{(25)}$.

In our study, there was no significant difference as regards Carotid Duplex data ( $p$ $>0.05$ ) which came in agreement with Lord et al. ${ }^{(25)}$.

The possible explanation that extracranial arterial stenosis (EAS) had little effect on END in comparison to intracranial stenosis is that brain region affected by IAS is more likely to have a limited collateral blood flow whereas in EAS, collaterals across the circle of Willis maybe preserved allowing the perfusion into a brain region distal to the occlusion.

This came in disagreement with Siegler et $a .^{(19)}$ who reported that The presence of carotid stenosis was found to be a risk factor for ND (unadjusted OR 1.80; 95\% CI 1.10$3.10 ; \mathrm{P}=.0298)$, and interestingly, this relationship remained independent regardless of the side of the stenosis in relation to the side of the cerebral infarct.

Our results disagree with Weimar et al. ${ }^{(26)}$ reported that patients with END had posterior circulation stenosis more than patients without END with highly significant statistical difference (VA $(\mathrm{P}=0.002), \mathrm{BA}$ $(\mathrm{P}<0.001)$ and PCA $(\mathrm{P}<0.001)$ and anterior cerebral artery $(p=0.007)$.

Regarding follow up data: there was highly significant decrease in day-1,2 and day-3 SBP and DBPs, in END group; compared to non-END group; with highly significant statistical difference $(p<0.05$ respectively) which came in agreement with Kang in $2017^{(27)}$.

The role of BP becomes particularly important whenever a large volume of hypo perfused but still viable tissue, susceptible to changes in systemic BP is present. Indeed, in this case, any drop in BP cannot be compensated for by auto regulatory mechanisms, which can in turn lead to tissue infarction ${ }^{(28)}$. When the changes in systolic BP during the first day were taken into account in a logistic regression, patients with a decrease in systolic BP $20 \mathrm{~mm} \mathrm{Hg}$ showed significantly increased odds of END ${ }^{(29)}$.

In our study, systemic complication (pneumonia, hematemesis, myocardial infarction) was more prevalent in END group; compared to non-END group; with highly significant statistical difference $(p<$ 0.05 respectively) which came in disagreement with Kwan in 2006 Kwan and Hand, ${ }^{(8)}$.

In our study, 17 patients with END (34\%) had systemic complication. This was higher than reported by other studies. Siegler et al. (19) (using the same definition for END) reported 35 out of 323 patients had systemic complication (11\%). Lord et al. ${ }^{(25)}$ reported 5 out of 98 patients had systemic complication $(5 \%)$.

In our sample $29.7 \%$ had territorial infarction (large stroke) and 37.8\% (108 patients) had intracranial arterial stenosis and $22.4 \%$ (64 patients) had MCA disease. This means that our sample had large number of severe stroke which make them 
more prone for complication like aspiration pneumonia.

There was no significant difference as regards UTI and DVT complications ( $\mathrm{p}>$ $0.05)$ which came in agreement Kwan and Hand, ${ }^{(8)}$.

In our study, we assessed neurological complication in 40 patients $(80 \%)$ of END group. $27(67.5 \%)$ of them had abnormality in follow up imaging (14 patients had hemorrhagic transformation (35\%), 9 patients had malignant brain edema $(22.5 \%)$ and 4 patients had stroke progression (10\%).

Siegler et al. ${ }^{(19)}$ studied causes of END in 323 patients within the first day after stroke and founded that 86 patients had progressive stroke $(26.6 \%), 23$ patients had hemorrhage $(7 \%), 10$ patients had new stroke $(3 \%)$ and 34 patient had brain edema (10.5\%). Among 231 patients with END within the first day after acute ischemic stroke studied by Davalos et al. ${ }^{10)} 61$ patients had hemorrhage $(27 \%)$ and 48 patients had malignant brain edema $(21 \%)$. Weimar et al. ${ }^{(26)}$ studied 256 patients with END and founded that $33.6 \%$ had progressive stroke, $27.3 \%$ had brain edema and $10.5 \%$ had hemorrhage.

As regard GCSs, there was highly significant decrease in day-1,2 and 3 GCSs, in END group; compared to non-END group; with highly significant statistical difference $(p<0.01$ respectively) which came in agreement with Lord in $2015^{(25)}$.

Lord et al. ${ }^{(25)}$ Reported that Compared with those with No END at any point during the study, patients with END were more likely to have lower GCS (END versus No END; 13 versus 15 ; $\mathrm{P}<0.001$ ).

Logistic regression analysis showed that; after applying (Backward method) and entering some predictor variables; the increase in age, HTN duration, NIHSS-b, DWSI, MCA, and Hemorrhagic transformation; had an independent effect on increasing the probability of END occurrence; with significant statistical difference ( $p<0.05$ respectively) which came in agreement with Nacu et al. ${ }^{(17)}$ as regard NIHSS-b and MCA occlusion, Bathia et $a .^{(6)}$ and Geng et al. ${ }^{(18)}$ as regard baseline NIHSS and diabetes. Siegler et al. ${ }^{(19)}$ as regard age baseline NIHSS. Weimar et al. ${ }^{(26)}$ as regard MCA occlusion and diabetes.

\section{Conclusion:}

- Early neurological deterioration is a frequent complication after acute stroke, with a poor short-term prognosis. This study provides that hyperglycemia, hyperuricemia and cardiac disease (IHD and AF) may increase the risk of END.

- Careful attention should be paid for patients with severe stroke and those with intracranial arterial disease to prevent or minimize the risk of complication like aspiration pneumonia and hemorrhagic transformation.

\section{Recommendation:}

- Effective treatment strategies are urgently needed to reduce the occurrence of END and its impact on outcome.

- Identifying all people at risk and control their risk factor is very important to avoid hazards and complications of END.

- This study is small size (300 patients) one center study, so: large multicenter study with long term follow up are needed to explore causes and predictors of early and late neurological deterioration and their effect on short and long term outcome.

\section{REFERENCES:}

1. Thanvi B, Treadwell S, Robinson T: Early neurological deterioration in acute ischaemic stroke: predictors, mechanisms and management. Postgrad Med J 2008, 84(994):412-417. 
Samia Ashour Mohamed Helal, et al.,

2. Sumer M, Ozdemir I, Erturk O. Progression in acute ischemic stroke: frequency, risk factors and prognosis. J Clin Neurosci 2003; 10:177-80.

3. Helleberg, Bernt Harald, Hanne Ellekjær, Gitta Rohweder, and Bent Indredavik. "Mechanisms, Predictors and Clinical Impact of Early Neurological Deterioration: The Protocol of the Trondheim Early Neurological Deterioration Study." BMC Neurology 2014:14 (1). 201-4.

4. Huang YC, Yuan-Hsiung Tsai, Jiann-Der Lee, Jen-Tsung Yang, and Yi-Ting Pan. "A Novel Neuroimaging Model to Predict Early Neurological Deterioration after Acute Ischemic Stroke." Text. 2018 https://doi.org/info:doi/10.2174/156720261 5666180516120022

5. Zhang Ying-Bo, Ying-Ying Su, Yan-Bo He, Yi-Fei Liu, Gang Liu, and Lin-Lin Fan. Early Neurological Deterioration after Recanalization Treatment in Patients with Acute Ischemic Stroke: A Retrospective Study. Chin Med J (Engl). 2018 Jan 20; 131(2): 137-143.

6. Bhatia Kunal, Smita Mohanty, B.K. Tripathi, B. Gupta \& M.K. Mittal. Predictors of early neurological deterioration in patients with acute ischaemic stroke with special reference to blood urea nitrogen (BUN)/creatinine ratio \& urine specific gravity. Indian J Med Res 141, March 2015, pp 299-307.

7. Siegler JE, Boehme AK, Kumar AD, et al. What change in the National Institutes of Health Stroke Scale should define neurologic deterioration in acute ischemic stroke? J Stroke Cerebrovasc Dis 2013; 22(5): 675-82.

8. Kwan J, Hand P. Early neurological deterioration in acute stroke: clinical characteristics and impact on outcome. QJM 2006; 99:625-33.

9. Phuong Vinh, Tran Van Huy. Prediction of acute stroke progression by the National Institutes of Health Stroke Scale. J Geriatr Cardiol 2007; 4:225-228.

10. Davalos A, Toni D, Iweins $F$, et al. Neurological deterioration in acute ischemic stroke: potential predictors and associated factors in the European Cooperative Acute
Stroke Study (ECASS) I. Stroke 1999;30:2631-6.

11. Mohr JP, Caplan LR, Melski JW, et al. The Harvard Cooperative Stroke Registry: a prospective registry. Neurology 1978; 28:754-62.

12. Marti-Vilalta JL, Arboix A. The Barcelona Stroke Registry. EurNeurol 1999; 41:13542.

13. Yamamoto H, Bogousslavsky J, van Melle G. Different predictors of neurological worsening in different causes of stroke. Arch Neurol 1998; 55:481-6.

14. Tei H, Uchiyama $S$, Ohara $K$, et al. Deteriorating ischemic stroke in 4 clinical categories classified by the Oxfordshire Community Stroke Project. Stroke 2000; 31:2049-54.

15. Steinke W, Ley SC. Lacunar stroke is the major cause of progressive motor deficits. Stroke 2002; 33: 1510-6.

16. Jorgensen HS, Reith J, Nakayama H, Kammersgaard LP, Houth JG, Raaschou $\mathrm{HO}$, Olsen TS. Potentially reversible factors during the very acute phase of stroke and their impact on the prognosis: is there a large therapeutic potential to be explored?Cerebrovasc Dis 2001; 11:20711.

17. Nacu A, Bringeland GH, Khanevski A, Thomassen L, Waje- Andreassen U, Naess $H$. Early neurological worsening in acute ischaemic stroke patients. Acta Neurol Scand 2016: 133: 25-29.

18. Geng HH, MSa,b, Qiang Wang, PhD, MDa, Bo Li, PhDa, Bin-Bin Cui, MSd, et al. Early neurological deterioration during the acute phase as a predictor of long-term outcome after first-ever ischemic stroke. Medicine (2017) 96:51.

19. Siegler JE, Alyana Samai, Eleanor Semmes, and Sheryl Martin-Schild. "Early Neurologic Deterioration after Stroke Depends on Vascular Territory and Stroke Etiology." Journal of Stroke 2018: 18 (2): 203-10.

20. Aoki, Junya, Yasuyuki Iguchi, Kazumi Kimura, Kensaku Shibazaki, Takeshi Iwanaga, and Kenichiro Sakai. "Diameter of the Basilar Artery May Be Associated 
with Neurological Deterioration in Acute Pontine Infarction." European Neurology 2010: 63 (4): 221-26.

21. Miyamoto, Nobukazu, Yasutaka Tanaka, Yuji Ueno, Miyako Kawamura, Yoshiaki Shimada, Ryota Tanaka, Nobutaka Hattori, and Takao Urabe. "Demographic, Clinical, and Radiologic Predictors of Neurologic Deterioration in Patients with Acute Ischemic Stroke." Journal of Stroke and Cerebrovascular Diseases 2013: 22 (3): 205-10.

22. Wu H, Jia Q, Liu G, Liu L, Pu Y, Zhao X, et al. Decreased uric acid levels correlate with poor outcomes in acute ischemic stroke patients, but not in cerebral hemorrhage patients. J Stroke Cerebrovasc Dis 2014; 23: 469e75.

23. Kellert L, Martin E, Sykora M, Bauer H, Gussmann P, Diedler J, Herweh C, Ringleb PA, Hacke W, Steiner T, Bösel J. Cerebral oxygen transport failure?: decreasing hemoglobin and hematocrit levels after ischemic stroke predict poor outcome and mortality: STroke: RelevAnt Impact of hemoGlobin, Hematocrit and Transfusion (STRAIGHT)--an observational study. Stroke. 2011 Oct; 42(10):2832-7.

24. Khan MF, Ibrahim Shamael, Qamar Zaman, Asad Mahmood, and Maimoona Siddiqui .
Association of Anemia with Stroke Severity in Acute Ischemic Stroke Patients. Cureus. 2018 Jun; 10(6): e2870.

25. Lord, Aaron S., Emily Gilmore, H. Alex Choi, and Stephan A. Mayer. "Time Course and Predictors of Neurological Deterioration After Intracerebral Hemorrhage." Stroke 2015:46 (3): 647-52.

26. Weimar C, Mieck T, Buchthal J, Ehrenfeld CE, Schmid E, Diener HC, German Stroke Study C: Neurologic worsening during the acute phase of ischemic stroke. Arch Neurol 2005, 62(3):393-397.

27. Kang, Jihoon, Jeong-Ho Hong, Min Uk Jang, Nack Cheon Choi, Ji Sung Lee, Beom Joon Kim, Moon-Ku Han, and Hee-Joon Bae. "Change in Blood Pressure Variability in Patients with Acute Ischemic Stroke and Its Effect on Early Neurologic Outcome." Edited by Tatsuo Shimosawa. PLOS ONE 12 (12): PLoS One. 2017; 12(12): e0189216.

28. Zazulia AR, Videen TO, Powers WJ. Symptomatic autoregulatory failure in acute ischemic stroke. Neurology. 2007; 68:389390. 39.

29. Castillo J, Leira R, Moro MA, et al. Neuroprotective effects of aspirin in patients with acute cerebral infarction. Neurosci Lett 2003; 339:248-50. 


\section{Samia Ashour Mohamed Helal, et al.,}

تدهور الجهاز العصبي المبكر بعد السكتة الدماغية الحادة_المؤشرات والأسباب المحتملة وعلاقتها

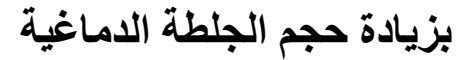

سامية عاشور محمد هلال وهاني امين عارف وأيمن محمد ناصف ورامز رضا مصطفى ومحمد أمير ترك، وايهاب عبدالباسط عبدالصمد ناهن

قسم المخ و الاعصابـ كلية الطب- جامعة عين شمس

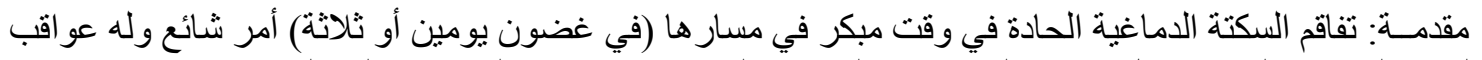

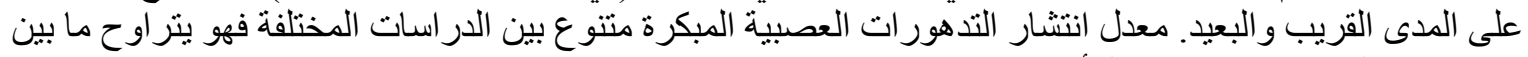
ثلاثة عشر إلى ثمانية وثلاثين بالمأة.

هدف العمل:

ا . . تحديد مدى انتشار وشدة وتوقيت التدهور ات العصبية المبكرة بعد السكتة الدماغية الحادة.

r r . تحديد العوامل و الأسباب المحتملة للتدهور ات العصبية المبكرة بعد السكتة الدماغية الحادة.

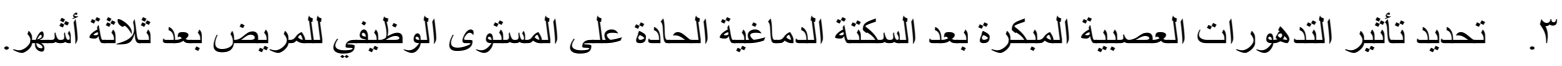

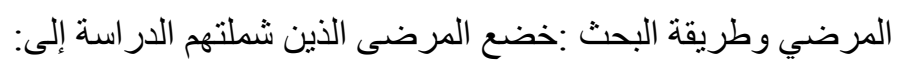

ا - التاريخ المرضي و الفحص العام و العصبي لتحديد العو امل الخطرة التي تؤدى إلى السكتة الدماغية مثل ارتفاع ضغط التها: الام و السكر والرفة الأذينية وجلطة القلب.

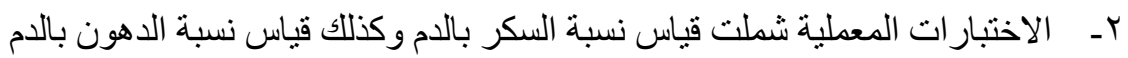

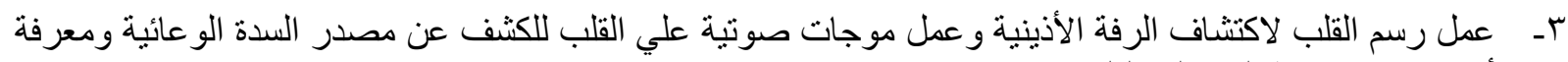
أثار ارتفاع ضغط الدم على القلب.

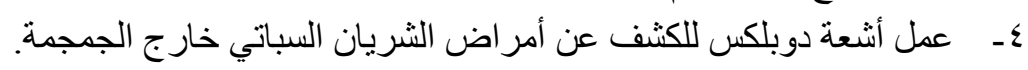

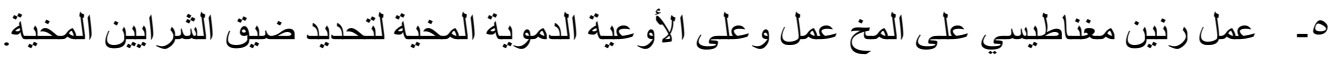

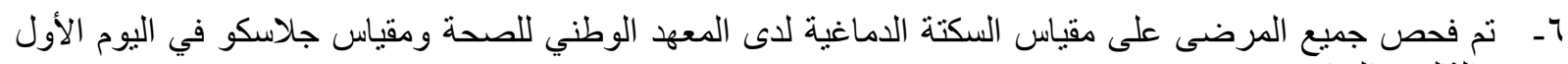

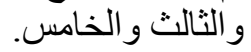

V- خضع جميع المرضى الذين يعانون من التدهورات العصبية المبكرة لإعادة الفحص بالرنين المغناطيسي أو الأشعة المقطعية.

^- جميع المرضى تم متابعتهم بعد ثناثة أشهر بعمل مقياس ر انكن المعدل.

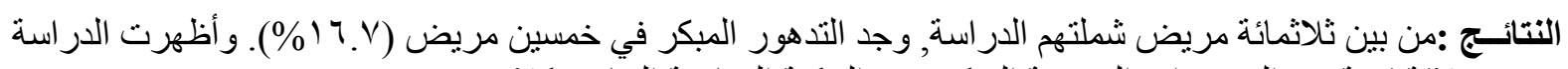

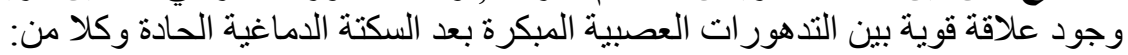

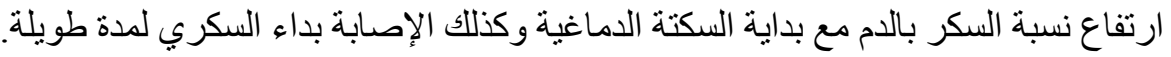

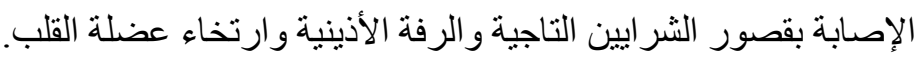

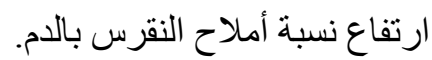

انخفاض ضغط الدم في بداية السكتة الدماغية وكذلك في الأيام التالية.

كبر حجم السكتة الدماغية من البداية وكذللك إصابة الثرية الثيان الأوسط من المئ.

كما أوضحت الدراسة أن التدهورات العصبية المبكرة بعد السكتة الدماغية الحادة يؤدي ارتفاع معدل الوفاة ونسبة الأبة العجز بعد السكتة الدماغية.

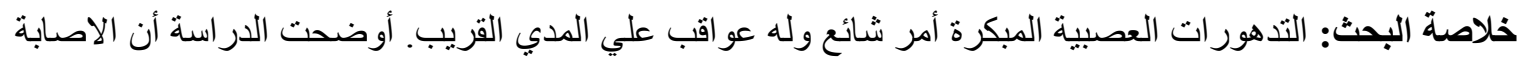

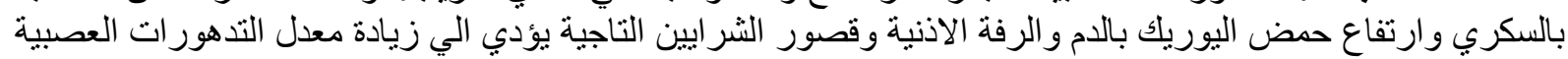

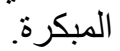

